\title{
Erratum to "In-Depth Analysis of Railway and Company Evolution of Yangtze River Delta with Deep Learning"
}

\author{
Renzhou Gui, Tongjie Chen (D), and Han Nie \\ The Department of Electronic and Communication Engineering, Tongji University, Shanghai 201804, China \\ Correspondence should be addressed to Renzhou Gui; rzgui@tongji.edu.cn \\ Received 14 May 2020; Accepted 15 May 2020; Published 11 June 2020 \\ Copyright (C) 2020 Renzhou Gui et al. This is an open access article distributed under the Creative Commons Attribution License, \\ which permits unrestricted use, distribution, and reproduction in any medium, provided the original work is properly cited.
}

In the article titled "In-Depth Analysis of Railway and Company Evolution of Yangtze River Delta with Deep Learning" [1], the contact details for Renzhou Gui were incorrect. The correct contact information is shown above.

\section{References}

[1] R. Gui, T. Chen, and N. Han, "In-depth analysis of railway and company evolution of Yangtze River Delta with deep learning," Complexity, vol. 2020, Article ID 5192861, 25 pages, 2020. 